\title{
Behavior of Sunscreen Usage Among Medical Students
}

\author{
Triana Novitasari $^{1}$, Subur Prajitno ${ }^{2}$, Diah Mira Indramaya ${ }^{3}$ \\ ${ }^{1}$ Faculty of Medicine Universitas Airlangga, Surabaya, Indonesia, \\ ${ }^{2}$ Department of Public Health and Prevention Medicine Faculty of Medicine Universitas Airlangga, \\ Surabaya, Indonesia. \\ ${ }^{3}$ Department of Dermatology and Venereology Faculty of Medicine Universitas Airlangga / Dr. \\ Soetomo General Academic Hospital, Surabaya, Indonesia,
}

\begin{abstract}
Background: Photoaging is an early skin aging process caused by sun exposure. Sunscreen is effective as a primary photoprotection to protect the skin from the dangers of ultraviolet radiation (UV) sunlight. However, sunscreen is often used in the wrong manner, so that it can reduce the effectiveness of the work of sunscreen. Purpose: To describe the knowledge and the practice of sunscreen usage among medical students of Universitas Airlangga and find out the relationship between the knowledge and the practice of sunscreen usage. Methods: This study is an analytic-observational study. Data were collected through questionnaire sheets that distributed to medical students of Universitas Airlangga class of 2016, 2017, and 2018. The results were analyzed using the Spearman test with a significance level of $1 \%$. Result: Obtained total respondents that fulfilled the inclusion criteria were 159 respondents, with $88.68 \%$ were female and $11.32 \%$ were male. Based on Fitzpatrick skin type, $55.97 \%$ respondents found with skin type-IV. There were $59.12 \%$ respondents got score of knowledge in the medium category and $64.78 \%$ respondents got score of practice also in the medium category. Based on analytic statistic correlation test between knowledge and practice of sunscreen usage, known that the significance value is equal to 0,006 with coefficient correlation is equal to 0.216. Conclusion: The knowledge and the practice of sunscreen usage among medical students of Universitas Airlangga is already in a fairly good range. There is a parallel relationship between the knowledge and the practice of sunscreen usage among medical students of Universitas Airlangga but with a low level of correlation strength.
\end{abstract}

Keywords: photoaging, sunscreen, behavior, knowledge, practice.

Correspondence: Diah Mira Indramaya, Faculty of Medicine Universitas Airlangga / Dr. Soetomo General Academic Hospital, Jl. Mayjen Prof. Dr. Moestopo 47 Surabaya 60131, Indonesia, Phone: +628123037841, e-mail: idiahmira@yahoo.com.

\section{INTRODUCTION}

Photoaging is a process of skin aging caused by sun exposure. ${ }^{1}$ Basically, the body has its mechanism for filtering sunlight, that is a melanin pigment. But if the skin exposed to sunlight chronically, it can cause damage to the skin. Consistent use of things that are protective against sunlight (photoprotective) is important to prevent photoaging, including to avoid the danger of ultraviolet (UV) rays. There are various forms of physical photoprotection, including endogenous factors, avoiding sunlight, staying in the shade, using clothing that covers the skin, or by using sunscreen. ${ }^{3}$

This photoprotection is very important for people who often do outdoor activities, one of them is a student. Student is required to always actively participate in various activities other than lecturing activities in class, for example following social service events that require students to go directly to the field, as well as other activities that are usually carried out in the context of community service. The use of photoprotection in students is highly recommended.

Sunscreen is the products combining several ingredients which protect the skin by absorbing, blocking or scattering UV radiation. ${ }^{2}$ Sunscreen is effective as a primary photoprotection to protect the skin from the dangers of sunlight. However, sunscreens are often used in the wrong manner or in less doses, and this allows significant deoxyribonucleic acid (DNA) damage to occur. ${ }^{4}$ For example, when sunscreen should be used as much as $2 \mathrm{mg} / \mathrm{cm}^{2}$ on skin surface, but most consumers use only $25-50 \%$ of the proper thickness. ${ }^{5}$

Table 1. Characteristics of the study sample

\begin{tabular}{cccc}
\hline No. & Questions & $\begin{array}{c}\text { Frequency } \\
(\mathrm{n}=159)\end{array}$ & $\%$ \\
\hline 1. & Gender : & 18 & 11.32 \\
& Male & 141 & 88.68 \\
\hline & Female & 0 & 0 \\
\hline 2. & Skin type based on Fitzpatrick scale : \\
I & 0 & 0 \\
II & 34 & 21.38 \\
III & 89 & 55.97 \\
IV & 36 & 22.65 \\
V & 0 & 0 \\
VI & & \\
\hline
\end{tabular}


Mistakes in the practice of sunscreen usage as described above will makes the aim of using sunscreen not optimal and not in accordance with the expected protection. Then in general, mistakes in practice in doing something will be based on their knowledge about it. Therefore, this study conducted with the aim to evaluating behavior, both the knowledge and the practice of sunscreen usage among medical students of Universitas Airlangga, as well as proving the relationship between knowledge and practice of sunscreen usage.

\section{METHODS}

This research is an analytic-observational study. The sample was determined using a purposive sampling method, with inclusion criteria, namely medical students of Universitas Airlangga, class of 2016, 2017 and 2018 who has been using sunscreen and who were willing to be the subject to the study by signing the informed consent sheet. Data was collected through questionnaire distributed to each class in the Faculty of Medicine, Universitas Airlangga. Then, the results were presented using descriptive statistical tables in the form of distribution tables and analyzed using a statistical correlation study.

The questionnaire is sourced from studies that have been carried out previously, conducted by Hadi et al. (2016) with the title "The Use of Sunscreen Products Among Final Year Medicine and Pharmacy Students: A Cross-sectional Study of Knowledge, Attitude, Practice, and Perception". ${ }^{20}$ These questions have been selected to fit the research variables that have been determined in this study and also has been tested for the validity of the items using the Pearson function in Microsoft Excel software version 15.26.

Spearman correlation tests have been conducted to analyze the correlation of knowledge variables and practice variables using IBM SPSS Statistics software version 23 for macOS.

\section{RESULTS}

A total 159 respondents met inclusion criteria and gave consent to participate in this study. Most of the samples were female $88.67 \%$ with the most skin type was skin type IV (55.97\%) as shown in Table 1 . The skin type was self-chosen by the respondents, according to the description of Fitzpatrick's classification in the questionnaire, associated with examples for each skin type.

In table 2 and table 3, the answers with letter "a" apostrophe $\left({ }^{a}\right)$ are the correct answer according to the journal reference.

Table 2 shows that there are $50.31 \%$ of respondents who know that sunscreen must be used even when they are indoors. Most respondents, $83.02 \%$, knew that broad spectrums sunscreens were better used in daily activities. As many as $73.59 \%$ of respondents know that sunblock must be used at least 15 minutes before being exposed to sunlight. Unsatisfactory results were obtained on the question of the number of sunscreens that must be used on the whole body of an adult (face, neck, back, chest, stomach, both hands, and legs), which is only $21.38 \%$ who answered correctly. As many as $60.38 \%$ of respondents know that the application needs to be repeated and at least once every 2 hours when outdoors activities. More than half of the respondents, $69.19 \%$, knew that sunscreens with greater sun protection factor (SPF) would be more effective at protecting skin from ultraviolet-B (UVB) radiation, but only $33.33 \%$ of respondents understood that the SPF level could not be used to measure the effectiveness of sunscreen protection against ultraviolet-A (UVA) radiation.

Table 3 shows that there were $66.04 \%$ respondents using sunscreen every day. All respondents $(100 \%)$ have used broad spectrum sunscreens. As many as $60.38 \%$ of respondents had applied sunscreen at least 15 minutes before being exposed to sunlight, but only $25.16 \%$ of respondents used the right amount of sunscreen, namely 1 teaspoon or more for the face only. Disappointing results were also obtained on the question of reapplying sunscreen, which is only $10.69 \%$ of respondents who reapply once every 2 hours during outdoors activities. As many as $70.44 \%$ of respondents have used a sunscreen with 30 SPF or more.

Table 4 shows that there were $59.12 \%$ and $64.78 \%$ of respondents who got score in the medium category about the knowledge and practice of using sunscreen (in sequence).

From table 5 to 7 , it can be seen that as many as $64.78 \%$ of respondents know the knowledge about the use of sunscreen from other options, namely from the internet and instructions for use listed on the sunscreen label, $59.12 \%$ choose the SPF size as a matter of consideration when choosing sunscreen products, and $33.96 \%$ chose other options, namely because of their self-awareness from reading magazines, the internet, and social media, also based on suggestions from family members to use sunscreen. In table 8 shows the results of the Spearman correlation statistical test, obtained significance value or Sig. (2-tailed) of 0.006, because the value of Sig. (2-tailed) 0.006 is smaller than 0.05 or 0.01 , it means that there is a significant relationship between the variables of knowledge and practice of using sunscreen. A correlation coefficient of 0.216 means that the level of strength of the relationship is in a very weak range. Correlation 
coefficient value is positive, which means the relationship is a direct relationship.

\section{DISCUSSION}

This study consisted of 141 female respondents and 18 male respondents. This may be due to the fact that women are more concerned about the use of sunscreen, as shown in the results of study conducted by Al Robaee (2010) that women tend to be more aware of sun exposure danger than men and take more protective measures including the use of sunscreen. ${ }^{6}$ The same thing was also found in study conducted by Paul et al. (2003), that women use sunscreen more often than men. ${ }^{7}$

Table 2. Knowledge of sunscreen usage

\begin{tabular}{|c|c|c|c|}
\hline No. & Questions & $\begin{array}{c}\text { Frequency } \\
(\mathrm{n}=159)\end{array}$ & $\%$ \\
\hline \multirow[t]{5}{*}{1.} & Frequency of sunscreen usage : & & \\
\hline & How often someone should be use sunscreen? & & \\
\hline & Always, even when in indoors ${ }^{a}$ & 80 & 50.31 \\
\hline & Every time will do outdoor activities & 79 & 49.69 \\
\hline & No need to use sunscreen & 0 & 0 \\
\hline \multirow[t]{4}{*}{2.} & Type of sunscreen : & & \\
\hline & What type of sunscreen is better for daily use? & & \\
\hline & Broad spectrum $^{\mathrm{a}}$ & 132 & 83.02 \\
\hline & Non-broad spectrum & 27 & 16.98 \\
\hline \multirow[t]{5}{*}{3.} & Time of application: & & \\
\hline & When should someone apply sunscreen? & & \\
\hline & Immediately before sun exposure & 17 & 10.69 \\
\hline & 5 minutes before sun exposure & 25 & 15.72 \\
\hline & $\geq 15$ minutes before sun exposure ${ }^{a}$ & 117 & 73.59 \\
\hline
\end{tabular}

4. Amount of sunscreen usage :

How much sunscreen is needed to cover the entire average adults' body?

3 teaspoons 13

6 teaspoons $^{\mathrm{a}} \quad 34$

12 teaspoons 18

I apply what I think is enough

$94 \quad 59.12$

5. Reapplication of sunscreen usage :

Does the application of sunscreen need to be reapplied during do outdoor activities?

$\begin{array}{lll}{\text { Yes, every } 2 \text { hours }^{\text {a }}} & 96 & 60.38 \\ \text { Yes, every less than 2 hours } & 46 & 28.93 \\ \text { No need to be reapplied } & 17 & 10.69\end{array}$

6. Knowledge of SPF :

Product A has an SPF of 30. Product B has an SPF of 15. Which product is more effective at protecting against $\mathrm{UVB}$ radiation?

$\begin{array}{lcc}\text { Product } \mathrm{A}^{\mathrm{a}} & 110 & 69.19 \\ \text { Product B } & 10 & 6.29 \\ \text { Not enough info to make determination } & 49 & 30.82\end{array}$

7. Knowledge of SPF :

Product A has an SPF of 30. Product B has an SPF of 15. Which product is more effective at protecting against UVB radiation?

$\begin{array}{lll}\text { Product A } & 85 & 53.46 \\ \text { Product B } & 21 & 13.21 \\ \text { Not enough info to make determination }^{\text {a }} & 53 & 33.33\end{array}$

\footnotetext{
Note :

$\mathrm{a}=$ correct response

$\mathrm{SPF}=$ Sun Protection Factor

$\mathrm{UVB}=$ Ultraviolet $-\mathrm{B}$
} 
Table 3. Practice of sunscreen usage

\begin{tabular}{|c|c|c|c|}
\hline No. & Questions & $\begin{array}{c}\text { Frequency } \\
(\mathrm{n}=159)\end{array}$ & $\%$ \\
\hline \multirow[t]{5}{*}{1.} & Frequency of sunscreen usage : & & \\
\hline & How often do you use sunscreen? & & \\
\hline & Every day ${ }^{\mathrm{a}}$ & 105 & 66.04 \\
\hline & Sometimes & 54 & 33.96 \\
\hline & Never & 0 & 0 \\
\hline \multirow[t]{3}{*}{2.} & Type of sunscreen that be used: & & \\
\hline & Broad spectrum $^{\mathrm{a}}$ & 159 & 100 \\
\hline & Non-broad spectrum & 0 & 0 \\
\hline \multirow[t]{4}{*}{3.} & Time of application : & & \\
\hline & When do you use sunscreen? & & \\
\hline & Less than 15 minutes before sun exposure & 63 & 39.62 \\
\hline & More or precisely 15 minutes before sun exposure ${ }^{a}$ & 96 & 60.38 \\
\hline \multirow[t]{4}{*}{4.} & Amount of sunscreen : & & \\
\hline & How much sunscreen that you use to cover the face? & & \\
\hline & Less than 1 teaspoon & 119 & 74.84 \\
\hline & Precisely 1 teaspoon or more ${ }^{a}$ & 40 & 25.16 \\
\hline \multirow[t]{5}{*}{5.} & Reapplication of sunscreen : & & \\
\hline & How often you reapply sunscreen during outdoor activities? & & \\
\hline & Every 2 hours ${ }^{\mathrm{a}}$ & 17 & 10.69 \\
\hline & Every more than 2 hours & 61 & 38.37 \\
\hline & Never reapply & 81 & 50.94 \\
\hline \multirow[t]{5}{*}{6.} & SPF value that be used: & & \\
\hline & How much SPF value that you use? & & \\
\hline & $<15$ & 0 & 0 \\
\hline & $15-29$ & 47 & 29.56 \\
\hline & $\geq 30^{\mathrm{a}}$ & 112 & 70.44 \\
\hline
\end{tabular}

Note :

$\mathrm{a}=$ correct response

$\mathrm{SPF}=$ Sun Protection Factor

Table. 4 Knowledge and practice of sunscreen usage score

\begin{tabular}{|c|c|c|c|c|}
\hline No. & Category & Score Range & $\begin{array}{c}\text { Frequency } \\
(\mathrm{n}=159)\end{array}$ & $\%$ \\
\hline \multirow[t]{4}{*}{1.} & Knowledge of sunscreen usage & & & \\
\hline & High & $5-7$ & 45 & 28.3 \\
\hline & Moderate & $3-4$ & 94 & 59.12 \\
\hline & Low & $0-2$ & 20 & 12.58 \\
\hline \multirow[t]{4}{*}{2.} & Practice of sunscreen usage & & & \\
\hline & High & $5-6$ & 31 & 19.5 \\
\hline & Moderate & $3-4$ & 103 & 64.78 \\
\hline & Low & $0-2$ & 25 & 15.72 \\
\hline
\end{tabular}


Table 5. Information sources about the knowledge of sunscreen usage

\begin{tabular}{lcc}
\hline \multicolumn{1}{c}{ Question } & $\begin{array}{c}\text { Frequency } \\
(\mathrm{n}=159)\end{array}$ & $\%$ \\
\hline How did you find out about the knowledge above? & 8 & 5.03 \\
Parent & 14 & 8.81 \\
Doctor & 29 & 18.24 \\
Friend & 8 & 5.03 \\
Teacher & 103 & 64.78 \\
Other & & $\%$ \\
\hline
\end{tabular}

Note: respondent can choose more than 1 options

Table 6. Consideration in choosing sunscreen products

\begin{tabular}{lcc}
\hline \multicolumn{1}{c}{ Question } & $\begin{array}{c}\text { Frequency } \\
(\mathrm{n}=159)\end{array}$ & $\%$ \\
\hline What are your considerations in choosing sunscreen products? & & 35.22 \\
Type of skin & 56 & 59.12 \\
SPF value & 94 & 15.72 \\
Price & 25 & 13.83 \\
Brand & 22 & $\%$ \\
\hline
\end{tabular}

Note: respondent can choose more than 1 options

$\mathrm{SPF}=$ Sun Protection Factor

Table 7. Person who recommends to use sunscreen

\begin{tabular}{lcc}
\multicolumn{1}{c}{ Question } & $\begin{array}{c}\text { Frequency } \\
(\mathrm{n}=159)\end{array}$ & $\%$ \\
\hline Who recommends you to use sunscreen? & & 5.03 \\
Parent & 8 & 8.81 \\
Doctor & 14 & 18.24 \\
Friend & 29 & 5.03 \\
Teacher & 8 & 64.78 \\
Other & 103 & \\
\hline
\end{tabular}

Note: respondent can choose more than 1 options

Table 8. Analysis of the relationship between knowledge and practice of sunscreen usage

\begin{tabular}{|c|c|c|c|c|}
\hline \multicolumn{5}{|c|}{ Correlations } \\
\hline & & & Knowledge & Practice \\
\hline \multirow[t]{6}{*}{ Spearman's rho } & Knowledge & Correlation Coefficient & 1.000 & $.216^{* *}$ \\
\hline & & Sig. (2-tailed) & $\cdot$ & .006 \\
\hline & & $\mathrm{N}$ & 159 & 159 \\
\hline & Practice & Correlation Coefficient & $.216^{* *}$ & 1.000 \\
\hline & & Sig. (2-tailed) & .006 & • \\
\hline & & $\mathrm{N}$ & 159 & 159 \\
\hline
\end{tabular}

**. Correlation is significant at the 0.01 level (2-tailed).

Skin types can be classified on the Fitzpatrick scale based on the skin reactions to sun exposure and UV radiation. ${ }^{8}$ Based on the above research data, majority of respondents, $55.97 \%$ had skin types IV. This is consistent with the data mentioned in the journal article written by Knaggs (2009), where the majority of Asian people have relatively darker skin, usually type IV and above, compared to people in western countries. In addition, there are also differences between Asian communities themselves. Asian communities can be divided into Northeast Asian communities (China, Japan, Korea), Southeast Asia (Indonesia, Malaysia, Singapore, Thailand, Cambodia, Vietnam) and South or Central Asia (India, Pakistan, Sri Lanka, Bangladesh). The skin of Northeast Asian people tends to be brighter (where 
these countries have more seasons) compared to Southeast Asian people who are more exposed to sunlight because of its geographical location close to the equator. ${ }^{9}$

UVA rays have a longer wavelength, which is 320-400nm, compared to UVB (290-320nm) and ultraviolet-C (200-280nm, cannot reach the earth's surface). Therefore, UVA can penetrate glass, whereas UVB can be completely obstructed by glass. ${ }^{10}$ A study conducted by Lowe et al. (1995), shows that continuous exposure to UVA even at low doses can reduce the content of elastic tissue in the skin which will then cause photodamage. ${ }^{11}$ Thus, broad spectrum sunscreens still need to be used even though being active indoors, such as when indoors and in the car. From the research data, it was found that $50.31 \%$ of respondents had answered correctly, while the rest $(49.69 \%)$ still thought that sunscreen only needed to be used when outdoors.

Because not all sunscreen products are broad spectrum, it is important to read the information contained in the sunscreen product. Sunscreen with broad spectrum provides protection from UV radiation from the sun, both UVA and UVB, by absorbing and / or reflecting UV radiation before it can damage the skin. ${ }^{12}$ From the research data, most respondents $(83.02 \%)$ already understand that the sunscreen sun broad spectrum is a type of sunscreen that is better for use in daily activities.

Sunscreen must be applied at least 15 minutes before sun exposure to get maximum benefit from sunscreen in an amount of 1 ounce or equivalent to 6 teaspoons to cover the entire body of an average adult. $^{12,13}$ According to research conducted by Poh Agin (2006), based on a monograph, a sunscreen can provide a protection interval against solar UV radiation depending on the size of the SPF and minimal erythema dose (MED) for someone who uses it. ${ }^{14}$ Meanwhile according to the American Academy of Dermatology (2018) and US Food and Drug Administration (2019), sunscreen must be re-applied once every 2 hours when outdoor activities or immediately re-apply after swimming or sweating, according to the instructions for use on the sunscreen label, without seeing the large SPF sunscreen and MED owned by its users. ${ }^{12,13}$ Guidelines from the American Academy of Dermatology and US The Food and Drug Administration is used in this study, to assess the behavior of sunscreen re-application. From the research data it is known that the majority of respondents $(73.59 \%)$ have known that sunscreen must be used at least 15 minutes before exposure to sunlight, but only $21.38 \%$ of respondents know that the amount of sunscreen needed to cover the entire body of a person adult is as much as 6 teaspoons. More than half of the number of respondents $(60.38 \%)$ know that sunscreens need to be reapplied every 2 hours during outdoor activities.

Some respondents already knew that a high SPF value would provide more protection. However, this does not indicate that the respondent understands the relationship between SPF and UVA / UVB, as illustrated from the frequency distribution of questions number 6 and 7. Most respondents (69.19\%) know that the greater the SPF the greater the protection provided for UVB radiation, but only $33.33 \%$ of respondents understood that the information provided in the question was not enough to know the effectiveness of sunscreen to protect the skin from UVA radiation.

From the research data above it can be seen that the majority of respondents have used the right type of sunscreen. However, only a small proportion of respondents use the appropriate amount of sunscreen.

The sun emits harmful UV rays throughout the year. Even in cloudy weather, up to $80 \%$ of harmful UV rays can penetrate into the deep layers of the skin. ${ }^{15}$ Therefore, sunscreen needs to be used every day. ${ }^{16}$ From the research results it can be seen that more than half of the number of respondents $(66.04 \%)$ have used sunscreen with the right frequency, i.e. every day. And only $33.96 \%$ of respondents don't use sunscreen every day. The data is parallel with the frequency distribution data of knowledge about the appropriate frequency of sunblock use.

Very remarkable results can be seen from the data on the type of sunscreen used by respondents. All respondents $(100 \%)$ have used broad spectrum sunscreen. The data is not in accordance with the frequency distribution data of respondents' knowledge about the type of sunscreen that is better used, it can be seen from $16.98 \%$ of respondents who still believe that non-broad spectrum sunscreens are better used in daily activities. Thus, it can be indicated that most of the sunscreens scattered in the market have provided the benefits of protection against UVA and UVB (broad spectrum) radiation, so that respondents who have inadequate knowledge but in practice can do the right thing.

From the results of the study it can be seen that the majority of respondents $(60.38 \%)$ have used sunscreen at least 15 minutes before being exposed to sunlight. The data is continuous with the level of knowledge when using sunscreen, which is as much as $73.59 \%$ of respondents know that sunscreen needs to be used at least 15 minutes before being exposed to sunlight.

Unsatisfactory results were obtained in the frequency distribution of the number and re-application 
of sunscreen by respondents. Most respondents $(74.84 \%)$ use inadequate sunscreen which are less than one teaspoon for the face only, which is not enough to produce maximum protection that can be achieved by sunscreen. This can be caused by the poor level of knowledge regarding the amount of sunscreens by majority respondents. This is consistent with the results of research conducted by Thomsen et al. (1993), which shows that the average amount used by respondents is $0.5 \mathrm{mg} / \mathrm{cm} 2$, where the amount that should be used is $2 \mathrm{mg} / \mathrm{cm} 2 .^{17}$

In addition, although most respondents $(60.38 \%)$ knew that sunscreens need to be reapplied once every 2 hours while outdoors, but $89.31 \%$ respondents still make mistakes in reapplying sunscreens. In fact, $50.94 \%$ of respondents said they had never re-applied sunscreen. This indicates that the practice of reusing sunscreen is not only influenced by the knowledge possessed by respondents, but there are also other factors that can influence. As shown in the results of research conducted by Weig et al. (2019), namely there are several inhibiting factors for using sunscreen, including dislike of the texture of sunscreen, constraints on costs, and constraints on time. ${ }^{18}$

Based on research data, it can be seen that the majority of respondents $(70.44 \%)$ in practice have used sunscreen with an appropriate SPF value in accordance with those recommended by the American Academy of Dermatology (2018). The practice behavior was supported by the level of knowledge of the majority of respondents about the exact size of the SPF.

The total value of knowledge about the use of sunscreen can be obtained with a range of values between 0 to 7 . Overall, the majority of respondents $(59.12 \%)$ get a total value in the medium category. This indicates that the knowledge of Universitas Airlangga Faculty of Medicine students about the use of sunscreen is quite good.

However, there are some aspects that still need to be corrected and socialized, namely the number of sunscreens that should be used and the correlation between the SPF and the protective effect against UVA radiation. Whereas, only $50 \%$ respondents answer correctly in both question. The total practice value using sunscreen can be obtained with a range of values between 0 to 6 . Overall, the majority of respondents $(64.78 \%)$ get the total value in the medium category. This indicates that the practice of using sunscreen on Universitas Airlangga Faculty of Medicine students is quite good. However, there are some behaviors that still need more attention, namely the use of sunscreen with the right amount $(24.57 \%)$ and re-application of sunscreen with the proper frequency $(10.28 \%)$. Where, both of these practices have a number of respondents below 50\% who answer correctly.

From the results of the above study it can be seen that the internet and the usage instructions listed on the sunscreen label are the most widely used source of knowledge about the use of sunscreen by $64.78 \%$ respondents. This is different from the results of research conducted by Weinstein et al. (2001) which shows that television and magazines were the main source of their knowledge about the knowledge of sun protection. ${ }^{19}$

From the research data it can be seen that the amount of SPF was the most (59.12\%) considered by respondents in choosing a sunscreen product. This was consistent with the data obtained in a study conducted by Hadi et al. (2016), namely the majority of respondents consisting of 28 (45.9\%) pharmacy faculty students and $33(32.7 \%)$ medical faculty students, choosing sunscreen products based on their SPF size. ${ }^{20}$

An attitude can't automatically be appeared in form of an action (overt behavior). To make attitude become a real action, supporting factors or a condition that allows, among others, is a facility are needed. In addition to the facility factor, other factors are needed, such as support factors from other parties, for example friends, parents, etc. ${ }^{21}$

From the data above, it can be seen that the majority of respondents $(33.96 \%)$ used sunscreen on their awareness/desire themselves because they read magazines, the internet, and social media. This was different from the results of research conducted by Hadi et al. (2016), which shows that International Islamic University Malaysia medical faculty students had the highest influence from their friends to use sunscreen. ${ }^{20}$

Research by Turrisi et al. (1999), showed that there was statistically significant relationship between knowledge and the practice of using sunscreen, but the level of strength of the relationship was unknown. This was consistent with research data, which shows that there was a relationship between knowledge and practice of using sunscreen on Universitas Airlangga Faculty of Medicine Students but with a very weak level of strength. The practice of using sunscreen in daily life was not only influenced by the knowledge they had, but it can also be influenced by other factors.

Figure 1, explains that the practice of using sunscreen were influenced by respondents' attitudes towards the use of sunscreen. Where, even though the respondent had good knowledge, it was not an affirmation that respondent can accept (agree or not) with the information they had. 


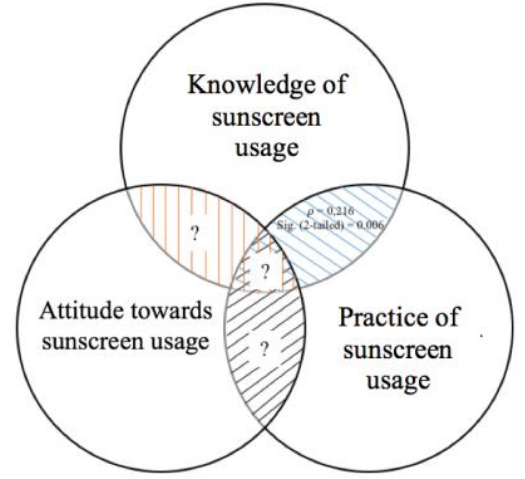

Figure 1. Diagram venn of sunscreen usage behavior.

The conclusion of this research is the knowledge and practice of using sunscreen on medical student of Universitas Airlangga is in a good range and there is a parallel relationship between the knowledge and practice of using sunscreen but with a low level of relationship strength. Suggestions from this study is that socialization needs to be done with a more enhanced frequency and do medical intervention by health services to improve the behavior of the use of sunscreen to the wider community by conducting counseling and demonstration of steps to use sunscreen. For further research, it is necessary to make a specific evaluation for why people don't use sunscreen.

\section{REFERENCES}

1. Pandel R, Poljšak B, Godic A, Dahmane R. Skin photoaging and the role of antioxidants in its prevention. ISRN Dermatol 2013; 1-11.

2. Shanbhag S, Nayak A, Narayan R, Nayak U. Antiaging and sunscreens: paradigm shift in cosmetics. Ad Pharma Bull 2019; 9(3): 348-59.

3. Friedman B, Lim H, Wang S. Photoprotection and Photoaging. Princip Pract Photoprot. 2016;1(4):6174.

4. Krutmann J, Bouloc A, Sore G, Bernard B, Passeron T. The skin aging exposome. J Dermatol Sci 2017; 85(3): 152-61.

5. Jansen R, Osterwalder U, Wang S, Burnett M, Lim H. Photoprotection. JAAD 2013; 69(6): 867.e1867.e14.

6. Al Robaee A. Awareness to sun exposure and use of sunscreen by the general population. Bosn J Basic Med Sci 2010; 10(4): 314-18.

7. Keeney S, McKenna H, Fleming P, McIlfatrick S. An exploration of public knowledge of warning signs for cancer. Eur J Oncol Nurs 2011; 15(1): 31 7.

8. Widemar K, Falk M. Sun exposure and protection index (SEPI) and self-estimated sun sensitivity. J Prim Prev 2018; 39(5): 437-51.
9. Qiu H, Long X, Ye J, Hou J, Senee J, Laurent A et al. Influence of season on some skin properties: winter vs. summer, as experienced by 354 Shanghaiese women of various ages. Int J Cosmet Sci 2011; 33(4): 377-83.

10. Wilson B, Moon S, Armstrong F. Comprehensive review of ultraviolet radiation and the current status on sunscreens. J Clin Aesthet Dermatol 2012; 5(9): $18-23$.

11. Thurstan S, Gibbs N, Langton A, Griffiths C, Watson R, Sherratt M. Chemical consequences of cutaneous photoageing. Chem Cent J 2012; 6(1): 34.

12. Sunscreen: how to help protect your skin from the sun [Internet]. FDA 2019 [cited 10 September 2019]. Available from: https://www.fda.gov/drugs/understanding-overcounter-medicines/sunscreen-how-help-protectyour-skin-sun

13. How to apply sunscreen [Internet]. AAD 2019 [cited 10 September 2019]. Available from: https://www.aad.org/sunscreen-apply

14. Geoffrey K, Mwangi A, Maru S. Sunscreen products: rationale for use, formulation development and regulatory considerations. Saudi Pharm J 2019; 27(7): 1009-18.

15. Gies P, van Deventer E, Green A, Sinclair C, Tinker R. Review of the Global Solar UV Index 2015 workshop report. Health Phys 2018; 114(1): 84-90.

16. Sunscreen FAQs [Internet]. AAD 2019 [cited 10 September 2019]. Available from: https://www.aad.org/media/stats/prevention-andcare/sunscreen-faqs

17. Sunscreen FAQs [Internet]. AAD 2019 [cited 10 September 2019]. Available from: https://www.aad.org/media/stats/prevention-andcare/sunscreen-faqs

18. Weig E, Tull R, Chung J, Brown-Joel Z, Majee R, Ferguson N. Assessing factors affecting sunscreen use and barriers to compliance: a cross-sectional survey-based study. J Dermatolog Treat 2019; 31(4): 403-5.

19. Saridi M, Toska A, Rekleiti M, Wozniak G, Liachopoulou A, Kalokairinou A et al. Sunprotection habits of primary students in a coastal area of Greece. J Skin Cancer 2012; 1-9.

20. Hadi H, Awadh A, Jamshed S, Elkalmi R. The use of sunscreen products among final year medicine and pharmacy students: a cross-sectional study of knowledge, attitude, practice, and perception. J Res Pharm Pract 2016; 5(3): 193.

21. Notoatmodjo S. Promosi kesehatan dan perilaku kesehatan. Jakarta: Rineka Cipta 2012; 45-62. 